\title{
Ultra-Wideband Monostatic Antenna for behind the Wall Detection
}

\author{
Jawad Ali ${ }^{1}$, Roshayati Yahya ${ }^{2}$, Noorsaliza Abdullah ${ }^{3}$, Syarfa Zahirah Sapuan ${ }^{4}$ \\ ${ }_{1,2,3,4}$ Department of Communication Engineering, Faculty of Electrical and Electronic Engineering, \\ Universiti Tun Hussein Onn Malaysia (UTHM), Johor, Malaysia \\ ${ }^{1}$ Department of Electrical Engineering, COMSATS Institute of Information Technology (CIIT), Lahore, Pakistan
}

\begin{tabular}{l} 
Article Info \\
\hline Article history: \\
Received Aug 11, 2017 \\
Revised Oct 22, 2017 \\
Accepted Nov 4, 2017 \\
\hline
\end{tabular}

Keyword:

Antennas

GPR technology

Monostatic antenna

Target detection

Ultra-wideband antenna

\begin{abstract}
This article introduces an ultra-wideband (UWB) shifted arc antenna, designed using Rogers RT-5880 Duroid substrate for the human detection behind the wall. The frequency for this proposed antenna ranges from $2.8-15.6 \mathrm{GHz}$ with the gain of around $6.05 \mathrm{~dB}$. A high gain for antenna has been achieved by the implementation of defected ground structure (DGS) method to make it a suitable configuration for through wall detection applications. For the verification of through wall detection configuration, a simulation-based experiment using ground penetrating radar (GPR) technology has been conducted. The results showed that proposed single antenna can act as a monostatic transceiver in order to detect human skin behind the concrete wall. Later, the reflections received from the target have been analyzed to detect and identify the antenna, wall and target for distance calculation.
\end{abstract}

Copyright () 2017 Institute of Advanced Engineering and Science. All rights reserved.

\section{Corresponding Author:}

Jawad Ali,

Faculty of Electrical and Electronic Engineering,

Universiti Tun Hussein Onn Malaysia (UTHM),

86400 Parit Raja, Johor, Malaysia.

Email: engrjawad.ali@outlook.com

\section{INTRODUCTION}

Ultra-wideband (UWB) is now a days popular technology used in antenna design for different communication applications. It mainly consists of a system having large operating bandwidth and less power consumption. The bandwidth greater than $500 \mathrm{MHz}$ is considered as UWB [1]. The free localization of UWB spectrum by the Federal Communications Commission (FCC) for industrial and scientific purposes, opened new gates of research to develop different technologies using UWB. The frequency band allocated for UWB technology ranges from $3.1-10.6 \mathrm{GHz}$ with the bandwidth of $7.5 \mathrm{GHz}$. There are several advantages of UWB including very large bandwidth, low power consumption, low cost of implementation, high data rate, and obstacle penetration capability [1]. These advantages widen the number of prominent applications in the field of communications such as Wireless Local Area Network (WLAN), Wireless Body Area Network (WBAN), WiMAX, and Wireless Personal Area Network (WPAN) [2]. Furthermore, UWB also being implemented in the field of radar like ground penetrating radars (GPR), imaging and positioning [3].

From last few decades there is a positive growth in UWB GPR applications for ground based study [4]. The number of GPR applications has been reported in the field of science and engineering for military and civilian applications, which includes the detection of land-mines, imaging through the wall, also in remote sensing methods for non-destructive testing of concrete and detection of people buried under-debris or in the opaque environment [5]. The implementation of UWB antenna technology in the applications of GPR involves different antenna designs such as horn, bow-tie, tapered slot, patch, spiral, and dipole have been designed previously. These antennas are considered for their gain, design complexity, directivity, and 
frequency bandwidth, which are the basic requirements of an antenna design for GPR applications [6-7]. In this paper, a shifted arc shaped UWB antenna using Rogers RT-5880 duroid as a dielectric substrate is proposed from 2.8 to $15.6 \mathrm{GHz}$ with the gain of around $6 \mathrm{~dB}$. Defected ground structure method is used to achieve the required gain while maintaining the UWB frequency band at the same time. Later, a monostatic transceiver (a term associated with the technology where a single antenna can be used as a transmitter as well as receiver) [6] based GPR experiment for behind the wall target detection is modeled and simulated using CST Microwave studio. Subsequently, the received reflections from the target is then computed and demonstrated using MATLAB.

The remaining paper is organized as follows; Antenna design based on RT-5880 with complete simulation model including wall and target using GPR technology is presented in next section. While, the discussion and analysis of obtained results are highlighted in results and discussion section. Final section summarizes the complete discussion in the form of conclusion.

\section{ANTENNA DESIGN AND SIMULATION-BASED EXPERIMENT}

The proposed antenna design and simulation-based ground penetrating radar experiment is performed using CST Microwave studio. In this section antenna design structure and experimental procedure is divided into two sub-sections. Section 2.1. presents about the designing of ultra-wideband antenna proposed for ground penetrating radar that is configurable for detection application, whereas Section 2.2. discussed about the simulation-based experiment containing antenna, obstacle and target models using CST Microwave studio.

\subsection{The Antenna Design}

To implement an ultra-wideband antenna design for GPR technology and to address the through wall penetration function, a planar shifted arc shaped antenna based on Rogers RT-5880 dielectric substrate with $\varepsilon_{\mathrm{r}}=2.2$ having defected ground structure characteristics is proposed during this paper. To achieve the arc shape of antenna, an elliptical patch radiator is designed first and then a partially circular slot is introduced towards the minor axis of elliptical patch. Later, this circular slot is further optimized by shifting it to adjust or tune the scattering parameter. The designed UWB arc antenna is shown in Figure 1(a), where the size in terms of antenna compactness is demonstrated by the dimensions of the substrate. This compactness of UWB antenna faced the challenge of bandwidth matching at lower frequency [8] over the band from 3-10GHz. To achieve the matching for whole band by maintaining the size compactness, a modified half grounded method is introduced in the design. However, the obtained gain is below the targeted value, whereas for GPR applications there should be the nominal gain. To achieve the targeted gain of $6 \mathrm{~dB}$, a DGS method [9] is used and the slots are added at the different areas of the ground as shown in Figure 1(b). These slots are the combination of even and uneven slots tuned to get the desired results. Table 1 shows the materials used in designing, dimensions of substrate as well as ground, the major and minor axis of the slotted arc along with the excitation port properties. The complete design discussed in this section is carried out for simulation using CST Microwave studio.

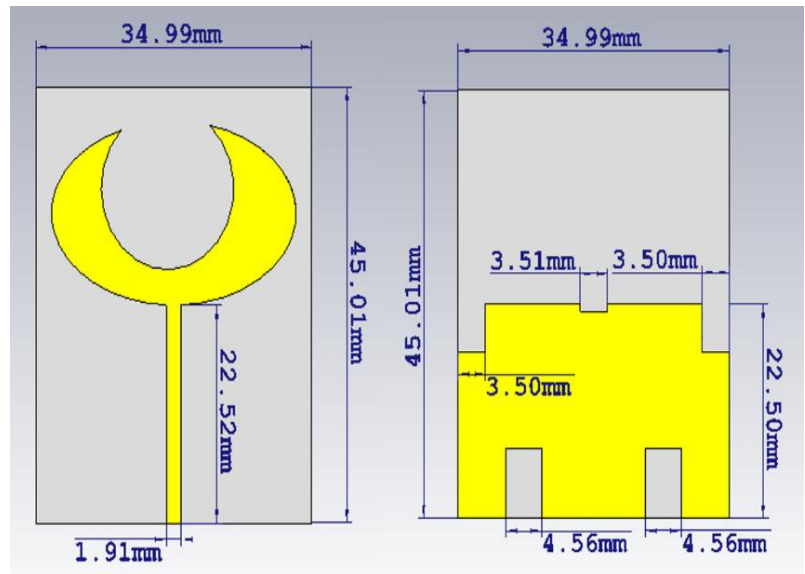

(a)

(b)

Figure 1. Design of shifted arc antenna: (a) Front view; (b) Back view 
Table 1. Parameters and dimensions of designed antenna

\begin{tabular}{ccc}
\hline Parameter & Type & Dimension $(\mathrm{mm})$ \\
\hline Major arc axis & Copper & 31 \\
Minor arc axis & Copper & 19 \\
Substrate $(\mathrm{LxW})$ & FR-4 & $45 \times 34.99$ \\
Ground $(\mathrm{LxW})$ & Copper & $25.5 \times 34.99$ \\
Port $(\mathrm{HxW})$ & Waveguide & $3.95 \times 7.14$ \\
\hline
\end{tabular}

\subsection{Experimental Model}

In previous section, the design of proposed antenna have been discussed. Meanwhile, this section carried out a discussion on detection behind the wall using GPR technology. Where a wave signal is transmitted, which penetrates through wall, hits the target and some of its energy is reflected back from the target towards the receiving antenna. Based on this concept, a simulation-based experiment is carried out to observe the detection capability of the compact shaped arc antenna. The detection scenario of complete experimental model is shown in Figure 2, where the monostatic antenna is used to transmit and receive signals. The antenna is placed at certain distances from a concrete wall with the thickness of $9 \mathrm{~cm}$. In the meantime, a targeted skin model of human in the form of rectangular block is placed behind the wall. The distance of the antenna to the wall is measured as Wall_D whereas the distance between the wall and target can be determined as Target_D, these defined distances can be varied accordingly to measure the penetration depth. The dielectric value of concrete wall is $\varepsilon_{\mathrm{r}}=5.46$ as it remained constant throughout the UWB frequency band, while during the experiment it has been observed that the dielectric value for skin varies [10] at different UWB frequencies with the value appears to be $\varepsilon_{\mathrm{r}}=26.31-36$. The design and experimental results of proposed model will be presented in results and discussions.

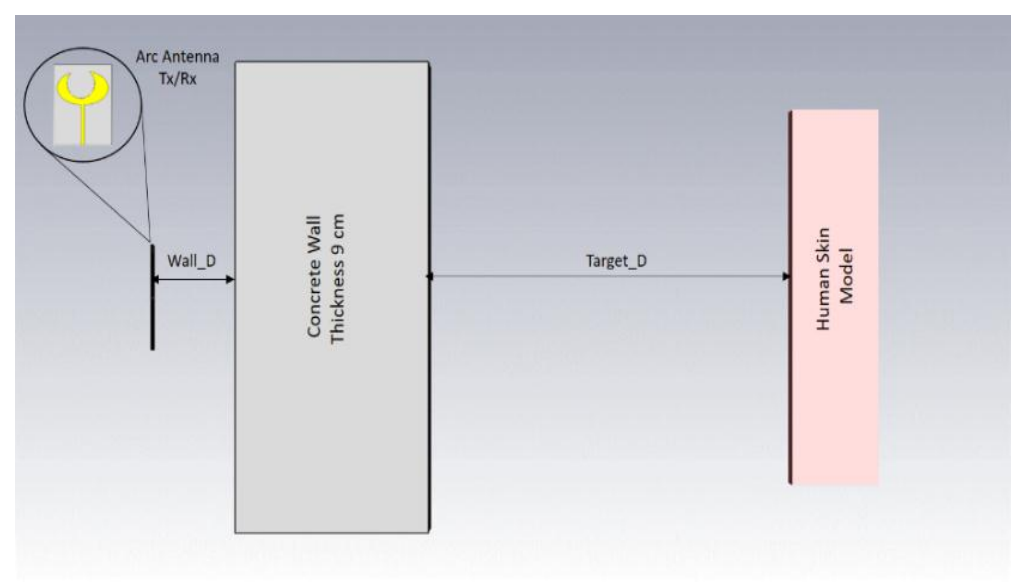

Figure 2. Simulation-based of experimental model

\section{RESULTS AND DISCUSSIONS}

The antenna proposed in this paper is designed using CST Microwave studio environment. The results obtained after simulations are shown in Figure 3. The reflection coefficient, $S_{11}$ in Figure 3(a) shows the significant result over the entire ultra-wideband, as the obtained band ranges from 2.8 to $15.6 \mathrm{GHz}$ with bandwidth of $12.8 \mathrm{GHz}$ which is more than the defined UWB band i.e. 3.1-10.6GHz. Another factor involved in the designing of UWB antenna for GPR applications is gain, which demonstrates the penetrating efficiency of the antenna. Figure $3(\mathrm{~b})$ represents the gain of proposed antenna as $6.05 \mathrm{~dB}$, this gain value is achieved by adding slots in the ground using defected ground structure technique. Different slots have been tried at different places on the ground to obtain the desired gain and as a result five uneven slots have been introduced in the design. Thus the resulted gain is helpful in detection behind the wall or under the debris as it also radiates in directional manner.

Subsequently, a simulation-based experimental setup is modeled for the detection application follows the GPR technique as discussed in previous section. The experimental results of monostatic antenna 
configuration are further analyzed in time domain by using Inverse Fast Fourier Transformation (IFFT) method to study the difference between obtained reflections from antenna, wall and target. The obtained time domain reflections of designed experiment is shown in Figure 4.

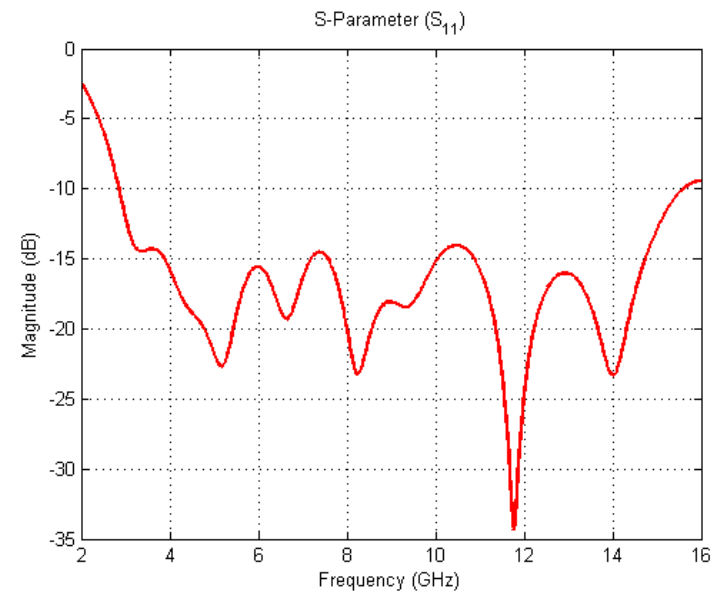

(a)

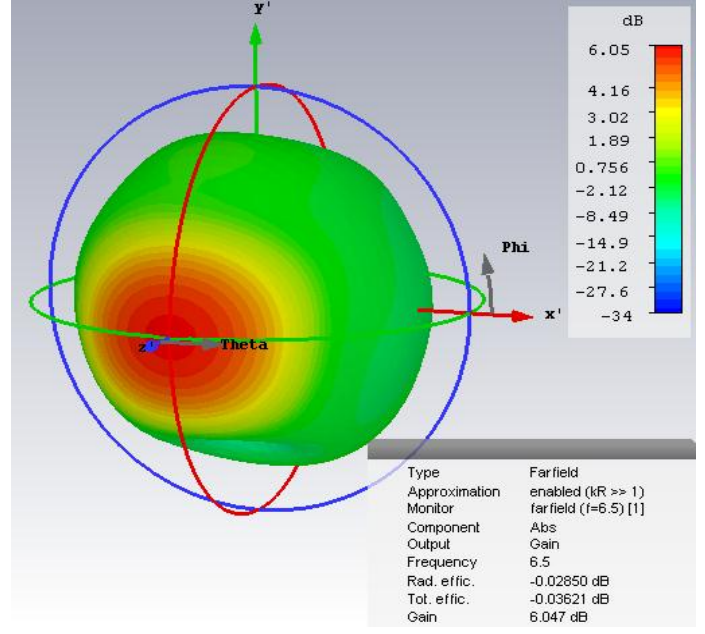

(b)

Figure 3. Simulation results for arc antenna: (a) $\mathrm{S}_{11}$ from 2.8-15.6GHz; (b) 3D simulated antenna gain

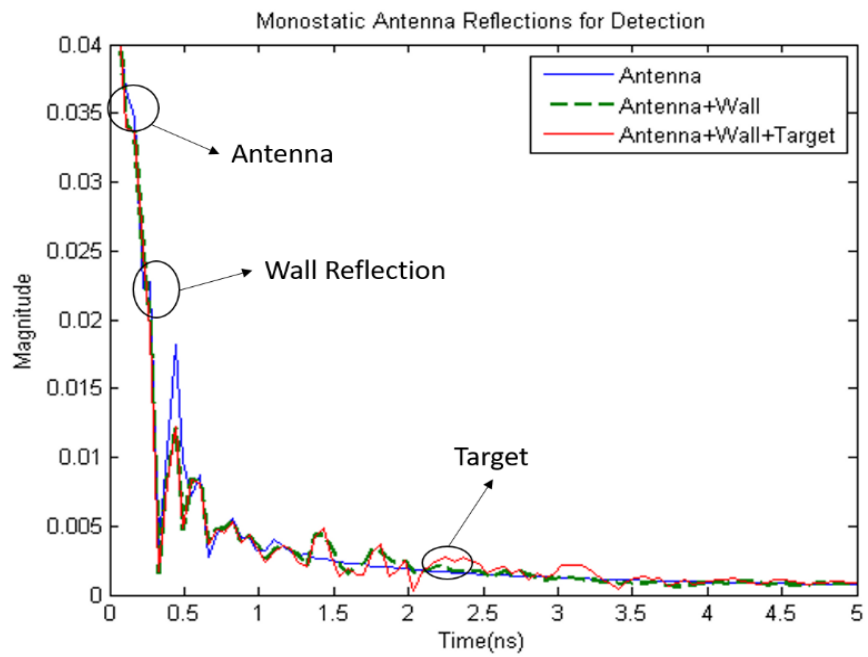

Figure 4. Antenna and target reflections

The first reflection in Figure 4 is obtained from the antenna, while the second with dash line is the one when antenna and wall simulated together, whereas the last line in red shows the reflection obtained from antenna, wall and target simulated together. Based on these reflections, it can be observed that the first reflection from the wall is obtained at $0.27 \mathrm{~ns}$. Meanwhile the reflection before $0.27 \mathrm{~ns}$ is the one from the antenna and at the obtained value, the antenna reflection faced the hurdle in the form of wall. The peak at $2.13 \mathrm{~ns}$ is the reflection from the targeted object behind the wall as it shows some disturbances in the obtained time domain reflections. From the obtained intervals of time $t$, the depth resolution $d$ from the antenna to the target can be determined by using Equations (1) and (2) [11]:

$$
d=v \frac{t}{2}
$$




$$
v=\frac{c}{\sqrt{\varepsilon_{r}}}
$$

In these Equations, $\mathrm{v}$ is the propagation velocity which is the ratio of speed of light $\mathrm{c}$ to dielectric value $\varepsilon_{\mathrm{r}}$ of the medium where the wave is travelling at the defined time. The obtained results are showing minor difference in the reflections of the antenna and wall. The main reason of this difference is aliasing that occurs mainly due to less number of samples [12].

\section{CONCLUSION}

A complete experimental model of ultra-wideband antenna to detect behind the wall has been discussed with obtained results. A shifted arc shaped patch antenna using RT-5880 dielectric substrate has been proposed with defected ground structure method having gain of $6.05 \mathrm{~dB}$ and the bandwidth of $12.8 \mathrm{GHz}$. Later, the designed antenna is simulated and modeled with the wall and skin structures to perform detection operation. The obtained analyzed time domain reflections showed the responses from antenna, wall and target. This analysis demonstrated that the proposed monostatic UWB antenna has the potential to detect the buried targets.

\section{ACKNOWLEDGEMENT}

The authors would like to acknowledge ORICC Universiti Tun Hussein Onn Malaysia (UTHM) for supporting this work.

\section{REFERENCES}

[1] D. Valderas, et al., "Ultrawideband antennas: Design and applications," London, Imperial College Press, 2010.

[2] F. B. Zarrabi, et al., "Triple-notch UWB monopole antenna with fractal Koch and T-shaped stub," $A E U$ International Journal of Electronics and Communications, vol. 70, pp. 64-69, 2016.

[3] A. Elboushi, et al., "Through Wall Gap Detection Using Monostatic Radar," Applied Computational Electromagnetics Society (ACES) Journal, vol. 28, pp. 411-418, 2013.

[4] C. Warren et al., "Experimental and Modeled Performance of a Ground Penetrating Radar Antenna in Lossy Dielectrics," IEEE Journal of Selected Topics in Applied Earth Observations and Remote Sensing, vol. 9, pp. 29-36, 2016.

[5] A. Ahmed, et al., "Design of UWB Antenna for Air-Coupled Impulse Ground-Penetrating Radar," IEEE Geoscience and Remote Sensing Letter, vol. 13, pp. 92-96, 2016.

[6] E. A. Etellisi, et al., "Wideband Monostatic Simultaneous Transmit and Receive (STAR) Antenna," IEEE Transactions on Antennas and Propagation, vol. 64, pp. 6-15, 2016.

[7] E. A. Etellisi, et al., "Wideband dual-mode monostatic simultaneous transmit and receive antenna system," in IEEE International Symposium on Antennas and Propagation (APSURSI), Fajardo, pp. 1821-1822, 2016.

[8] S. Koziel et al., "A Structure and Simulation-Driven Design of Compact CPW-Fed UWB Antenna," IEEE Antennas and Wireless Propagation Letters, vol. 15, pp. 750-753, 2016.

[9] R.A. Pandhare, et al., "Miniaturized microstrip antenna array using defected ground structure with enhanced performance," Engineering Science and Technology, an International Journal, vol. 19, pp. 1360-1367, 2016.

[10] N. M. Tamyis et al., "Dielectric properties of human skin in vivo in the frequency range 20-38GHz for 42 healthy volunteers," in Proceedings of the 28th URSI General Assembly, 2005.

[11] D. J. Daniels, “Ground Penetrating Radar," London, the Institution of Engineering and Technology, 2004.

[12] X. Zeng, et al., "Accuracy Evaluation of Ultrawideband Time Domain Systems for Microwave Imaging," IEEE Transactions on Antennas and Propagation, vol. 59, pp. 4279-4285, 2011. 


\section{BIOGRAPHIES OF AUTHORS}
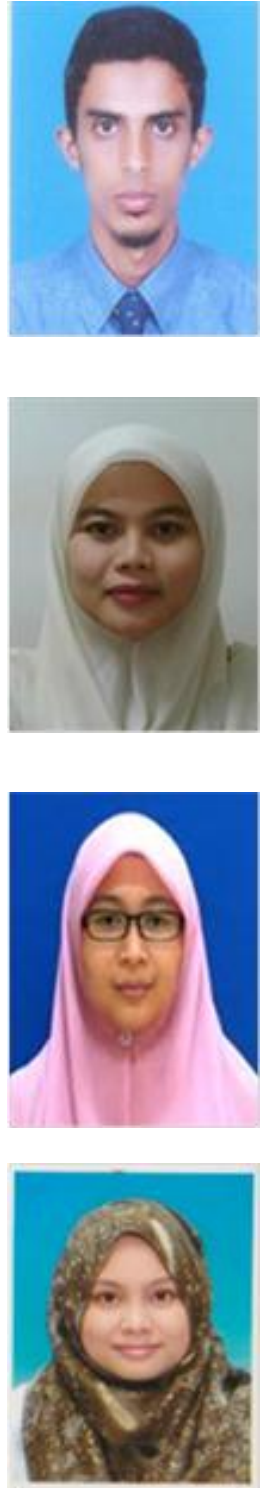

Jawad Ali received B.Eng. (Hons.) Electrical Engineering degree from The University of Lancaster, UK in 2014. Currently he joined Radio Communications and Antenna Design (RACAD) laboratory, where he is working towards his M.Eng. degree at Universiti Tun Hussein Onn Malaysia (UTHM), Johor, Malaysia. He Joined Electrical Engineering Department of COMSATS Institute of Information Technology (CIIT), Lahore, Pakistan in 2015, where he is associated with the cluster of Antenna and Radar Research Group. His research interests includes dielectric based material study, antenna designing, radar study and dual band transceiver.

Email:engrjawad.ali@outlook.com

Roshayati Yahya received her first degree in Universiti Tun Hussein Onn Malaysia (UTHM) in Electrical and Electronics Engineering (Telecommunication) in 2006. She joined UTHM in 2007 as a tutor and honored a Master degree in Electrical and Electronics-Telecommunications from Universiti Teknologi Malaysia (UTM) in 2009. She awarded a PhD in the same university as she was doing her M.Eng at Wireless Communication Centre (WCC), UTM. Her research interests including antenna design, RF and microwave, and antenna for biomedical engineering applications.

Email: rhayati@uthm.edu.my

Noorsaliza Abdullah received B.Eng. and M.Eng. degrees in Electronics and Telecommunications from the Universiti Teknologi Malaysia (UTM), Malaysia, in 2003 and 2005, respectively, and her Ph.D. degree from Shizuoka University, Shizuoka, Japan, in 2012. In 2003, she joined Universiti Tun Hussein Onn Malaysia (UTHM), Malaysia, as a Tutor and awarded a scholarship to further her M.Eng. and Ph.D. degrees. Her research interest include array antenna, adaptive beamforming, and mobile communications.

Email: nsaliza@uthm.edu.my

Syarfa Zahirah Sapuan received the B.Eng degree in Electrical Engineering (Hons) from Kolej Universiti Tun Hussein Onn Malaysia in 2003, M.Sc in Communication Engineering from Nanyang Technological University, Singapore in 2009 and PhD in Electrical Engineering from Universiti Tun Hussein Onn Malaysia (UTHM) in 2014. She is presently a Senior Lecturer in the Communication Engineering Department, UTHM and a Principle Researcher of the Electromagnetic Compatibility Research Cluster at the Research Center for Applied Electromagnetics, UTHM. Her research interests are Electromagnetic Compatibility, Antenna Calibration and Radio Frequency measurements.

Email: syarfa@uthm.edu.my 